\title{
Kain Hitam Cave (Painted Cave) Niah, Sarawak: The Relationship of Boat-Shaped Coffin and Rock Painting
}

\author{
Junior Kimwah, Humin Jusilin, Zaimie Sahibil \\ Faculty of Humanities, Arts and Heritage, \\ University of Malaysia Sabah, Jalan UMS, Kota Kinabalu 88400, Sabah, Malaysia \\ juniorkimwah@gmail.com, zumin198@yahoo.com, dasarlaut70@yahoo.com.my \\ Tel: +60178118940
}

\begin{abstract}
This paper discusses the relevance that exists in a cave used as a place of residence since the time of Neolithic. This archaeological site contains important artefacts that show modern civilization (homo sapiens) at the end of the Neolithic period. This research focuses on the cultural development of the ancient people through the discovery of artefacts in the Kain Hitam Cave. Preliminary findings show that ritual activities have been practised. Initial conclusions indicate that the ancient people practised animism. The linkages between the two aspects are essential in giving new insight into the cultural elements they were practising years ago.
\end{abstract}

Keywords: Kain Hitam Cave; boat-shaped coffin; cave painting; culture and interpretation.

eISSN: 2398-42870 2020. The Authors. Published for AMER ABRA cE-Bsby e-International Publishing House, Ltd.. UK. This is an open access article under the CC BYNC-ND license (http://creativecommons.org/licenses/by-nc-nd/4.0). Peer-review under responsibility of AMER (Association of Malaysian Environment-Behaviour Researchers), ABRA (Association of Behavioural Researchers on Asians) and cE-Bs (Centre for Environment-Behaviour Studies), Faculty of Architecture, Planning \& Surveying, Universiti Teknologi MARA, Malaysia.

DOI: https://doi.org/10.21834/ebpj.v5iSI3.2576

\subsection{Introduction}

Cave paintings found in Kain Hitam Cave or known as Painted Cave located in Niah, Sarawak are still unexplored historic sites. This research works to preserve the national heritage so that it does not disappear without any detailed record. The study on this site is conducted to find and record all the evidence in a research site.

Archaeological research should be reinforced to provide knowledge to the public. Archaeology is a study and survey that enriches the treasure of today's life through the numerous re-discoveries of the remains of art and human-made materials of the past. The importance of this research lies in the discovery of artefacts and information obtained and how it contributes to better humanitarian development by taking lessons from past events. Grahame Clark (1970: 40-41) argues that the importance of world prehistory is its contribution to expanding the historical perspective according to today's needs.

In the past, the basis of humanity is that human groups are organized through the inherited traditions. This knowledge of culture is shared by individual members of society that not only work to raise awareness about unity but to distinguish them from others. For example, the prehistoric site in the Kain Hitam Cave (Painted Cave) that describe the past human life activities in the past.

The reference to similar research is done by Tom Harrison and his wife, Barbara Harrison. He conducted an excavated at the site of Painted Cave in 1964. The cave is entirely separate from the main cave, the Niah Great Caves (West Mouth). When the excavation

eISSN: 2398-4287○ 2020. The Authors. Published for AMER ABRA cE-Bsby e-International Publishing House, Ltd., UK. This is an open access article under the CC BYNC-ND license (http://creativecommons. org/licenses/by-nc-nd/4.0). Peer-review under responsibility of AMER (Association of Malaysian Environment-Behaviour Researchers), ABRA (Association of Behavioural Researchers on Asians) and cE-Bs (Centre for Environment-Behaviour Studies), Faculty of Architecture, Planning \& Surveying, Universiti Teknologi MARA, Malaysia. DOI: https://doi.org/10.21834/ebpj.v5iSI3.2576 
was done in the cave, cave paintings were found on cave walls and casket boat-coffins of the corpse. During research done in the 1960s, they discovered that the cave was full of elements of past society prehistoric paintings. Hence, this research is meaningful in attempting to record historical periods in Sarawak.

\subsection{Method}

The data obtained in research is systematically made to ensure that the sites and historical materials collected are still in good condition. It is to ensure that the analysis process can be carried out smoothly and effectively. The primary and secondary surveys are the methods for obtaining data at the research site. It was implemented taking into account various factors and side-effects that involve planning, management, and purposes of research and based on established discipline standards. The question of scientific study or research is assessed based on these stages.

The observation method is very essential in implementing this research. Researchers first make a particular observation of each element to be studied. Researchers then take the data in detail and record each one of the data clearly and in order. Each data retrieval process is also recorded through digital camera recording to assist in the aspect of the research material preservation process. A survey is vital for a researcher to collect data for a site surveyed. Part of the evidence has been found on the site through the pattern of the distribution of locations in the Kain Hitam Cave (Painted Cave). An interview procedure is also essential to support the findings that been record in the effort to make the results of valid and proper quality research. The interview process was carried out to the Sarawak Museum staff who had responded to the support of research findings. An interview is a method in qualitative research involving conversations between researchers and subjects of meetings to obtain relevant information for the study. Through discussions, data collected from observations can be reinforced and complemented. This method was intended as a triangulation designed to verify the data or information collected.

This research was carried out a thorough research on the content contained in visual artwork. The content analysis focuses on image studies and interpretation of meaning in-depth and subjective. Content analysis research was used in media and communication but, the significant advantage of content analysis (qualitative) been done to examine media content based on contextual content and processes. Researchers see that contextual methods refer to the main content implicitly. Meanwhile, the aspect of the process involves interpreting the image carefully and repeatedly.

The analysis process of the data on the site is the most critical stage in this investigation. An analysis of artifacts depends on the type of objects found. Each method of analysis requires phased stages of research in generating comprehensive information. Physical study and the context of innovation or its role in culture were conducted to obtain information about the past human being (Fig. 1).

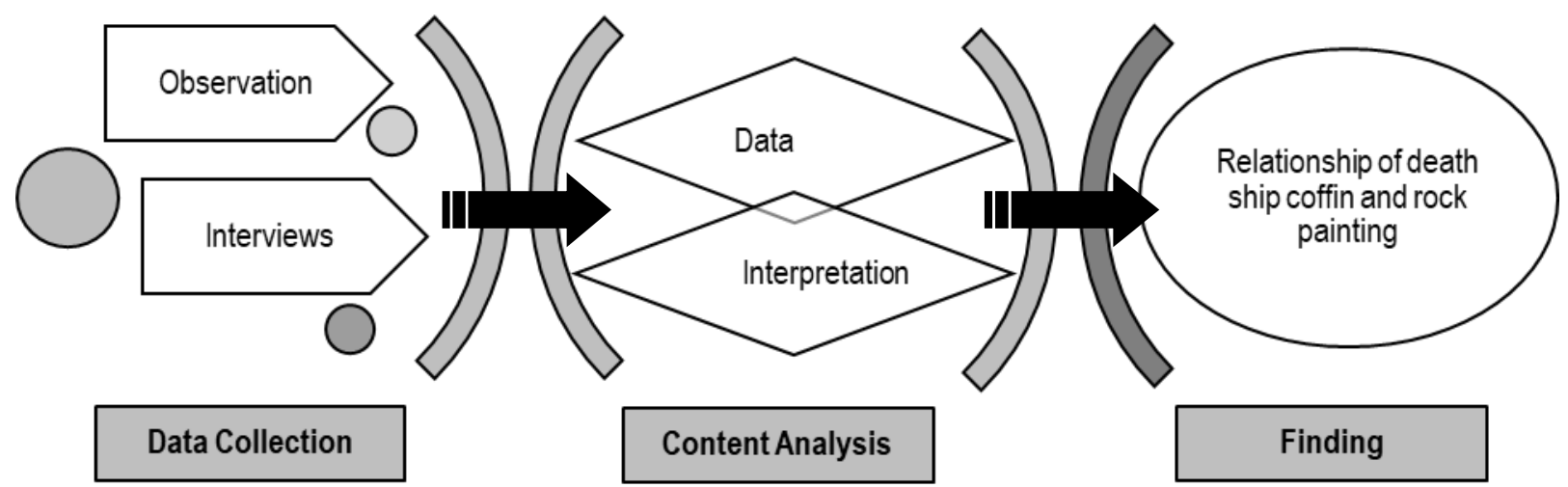

Fig.1: Procedure of research method.

\subsection{Results and Discussion}

To appreciate these works, researchers concentrate on writing toward issues that have become the inspiration of the ancient painter and explore the interpretation and the meaning of the issue. Researchers make an analysis and look for the essence of the subject and the images chosen by the ancient painter. Researchers seek to understand and deepen every aspect of the issue and make assumptions and summary the meaning of the artwork. Interpretation is a form of communication that is very useful in any process related to prehistoric heritage sites. It can attract visitors, delivering information in an effectively and engagingly. The interpretation method can also show visitors why a prehistoric heritage site has specific values to the community and country. Interpretation results can inspire visitors, awareness to the city to ensure the safety of ancient sites, and be aware of their significance. Zuliskandar Ramli \& Sanim Ahmad (2015: 35), explaining the findings of cave paintings at prehistoric sites in Malaysia prove that this ancient society has evolved in the way of thinking to translate all the activities they do in the form of cave paintings. Research conducted by scholars for a long time has supported the idea that cave paintings produced with hematite minerals are older than the cave paintings created by using charcoal. Among the cave paintings using haematite, mediums are found in Tambun Cave, Perak, and Kain Hitam Caves near 
Niah Great Caves in Sarawak (Fig.2). This cave painting describes hunting animals and human figures. Most impressive is the picture of boat used in cruise activities and is also used for funeral ceremonies especially as practiced in Niah Caves, Sarawak.

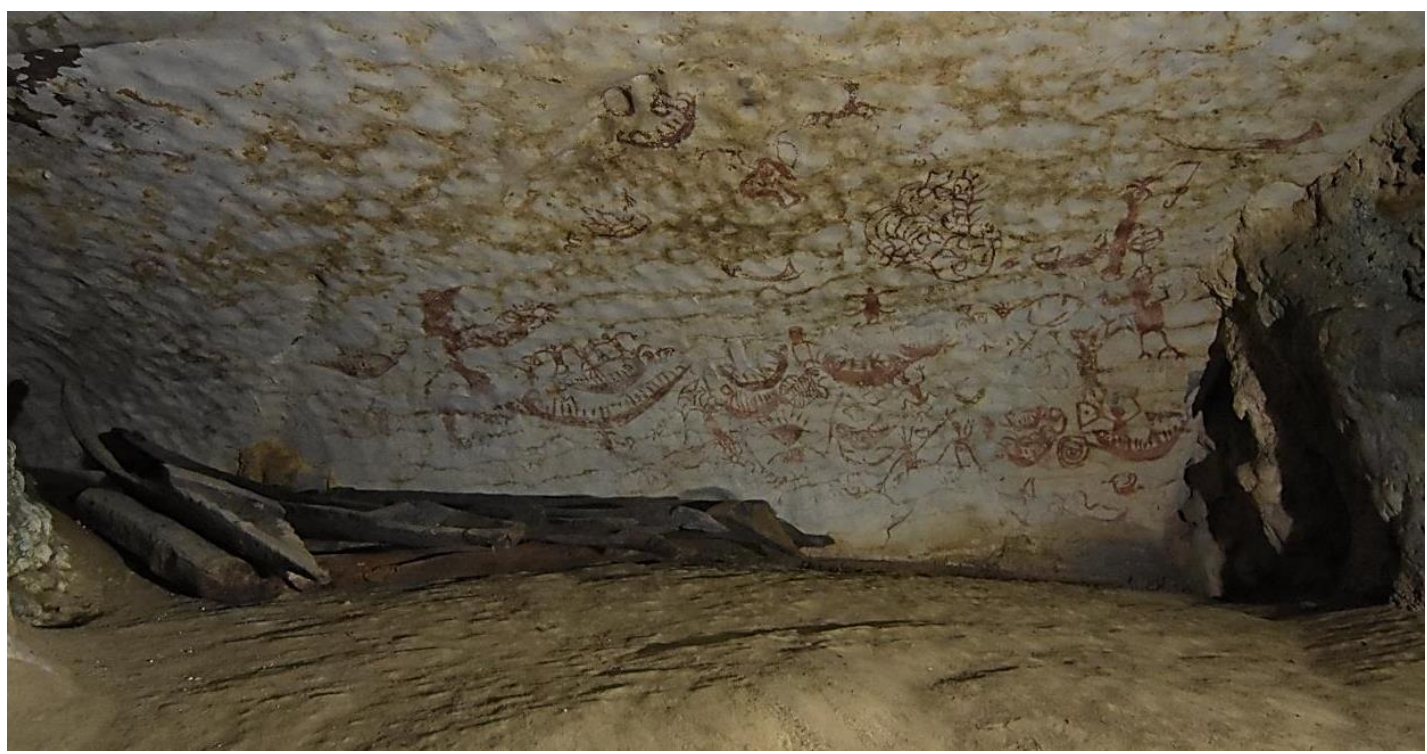

Fig.2: Prehistoric cave paintings.

The process of interpreting images on cave paintings is complicated if only based on the understanding of a researcher alone. In this research, researchers understand images based on the evidence and artifacts that have been found. This material is a source that can explain the phenomena and ceremonies conveyed by ancient people. Researchers are trying to translate the image and disassociate the meaning. In this cave painting, some photos have been identified based on the basic form features as in Fig. 3 (a), which shows the human figure on a boat while Fig. 3 (b) shows the image of the ship with the emerging tree.

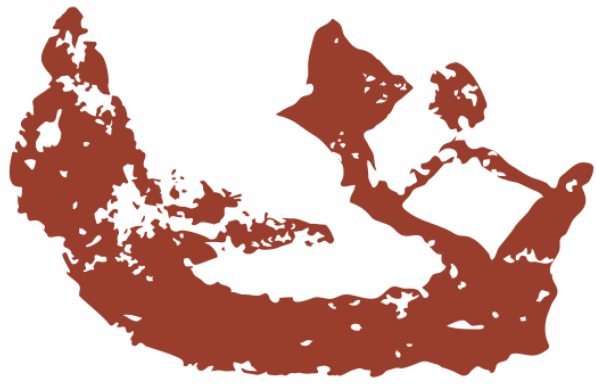

(a)

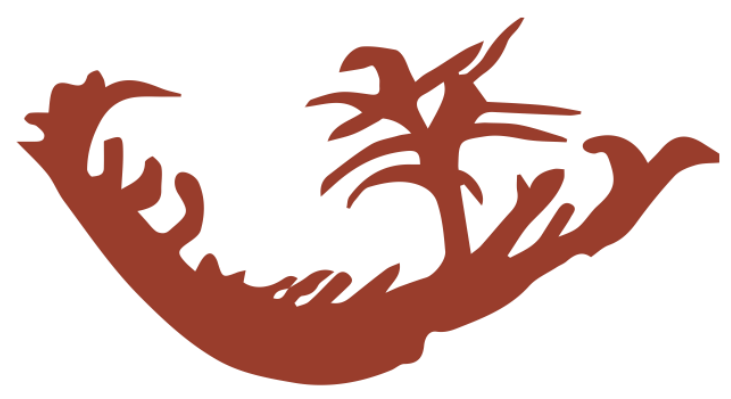

(b)

Fig.3: Boat image illustration (a) Human figure on a ship (b) Emerging tree from a boat.

Alland (1970: 40-41) discusses two aspects of adaptation. First is a long-term change that maintains a system journey concerning to its natural surroundings. Secondly are short-term adjustments that may or may not continue in the long run. An analysis of prehistoric human life as found in a site explains the adaptation or adaptation to the circumstances that took place at that time. The long-term interpretation of the changes shown from most locations is an example of a new consciousness that requires investigators to make adaptation analysis. The culture was usually considered to have a systematic pattern of arrangement so that its parts are merged in harmony. In this sense, culture was composed of multiple subsystems such as; technology, social, religion, ideology, and the economy. The basis of these assumptions is the small systems interacting or at least not harming other small systems. We can conclude that humans must behave inconsistently so that they do not interfere with the travel of the system. When people behave always, we can say that their behavior formed. Human beings in different cultures behave in different ways because their cultural patterns vary.

Radcliffe Brown (1952: 8-9) also explains that adaptation is an essential concept in the theory of evolution. This concept was applied to both types of research on the form of organic life and the type of social life among humans. An organism that exists will continue to exist if it adapts internally and externally. External adaptation is the adaptation of the body to the environment in which the living body was located. The difference between internal and external adaptations is simply a way of distinguishing the two aspects of the adaptation system. Its existence was for the organisms of a species. Likewise, with the ancient people who have adapted their way of life and used it as an idea to sketches on cave walls. The boat-shaped coffin is a representation of the stage of the end of a person's life. In this study, evidence of the concepts is valid and has been seen through the means of artifacts deployed on the 
discovery site, such as a boat coffin (Fig.4). These artifacts show the effect of divination, a fact that has been tested with various analysis methods. The proof that the punctuation exists is the first step since archaeologists use this fact to conclude the factors that cause such behavior. This effort is not easy because it must rely on ethnographic analogy or general hypotheses about the relationship between the artifacts and the behavior that founded on the research of the modern world.

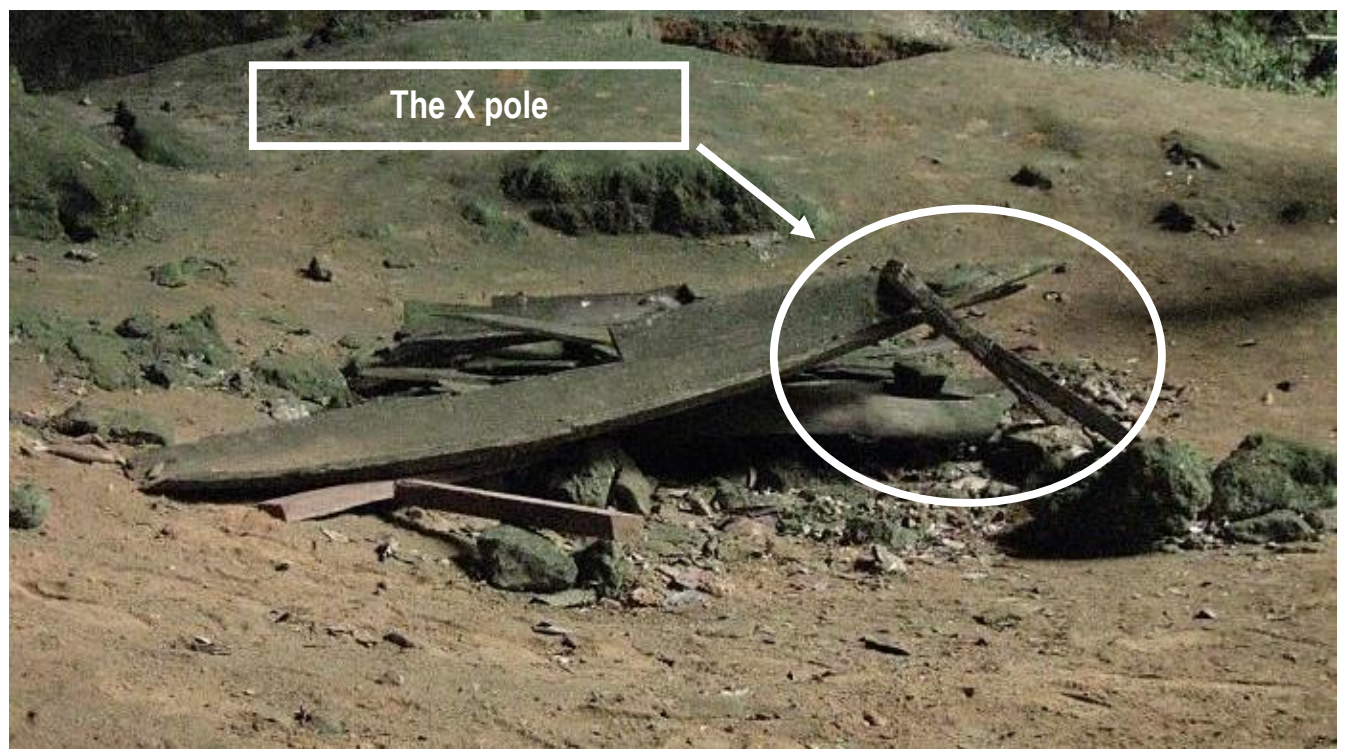

Fig.4: Artifact of the boat-shaped coffin.

The results of the initial analysis indicated that there is a link between the boat-shaped coffin artifacts placed beside the cave painting. This site was believed been used as a death chamber which is a place of settlement a long time ago. This was evidenced by several types of boat-shaped coffins that have been placed in the flat room of the Kain Hitam Cave. The casket of the boat was placed on a crossing pole, but now the mast has been broken (Fig.4). Artifacts such as beads, animal teeth, and ceramics were found in the nearby coffin area. Cave paintings produced are like a note of the daily activities of ancient civilizations (Fig.5). Boat images loaded with human figures are a representation of the voyage of life, which is a picture of sailing at the end of their lives. The Kain Hitam Cave position, which is relatively high above the slope of the ground, also proves to be a strategic area to be used as a sacred area for the ancient people.

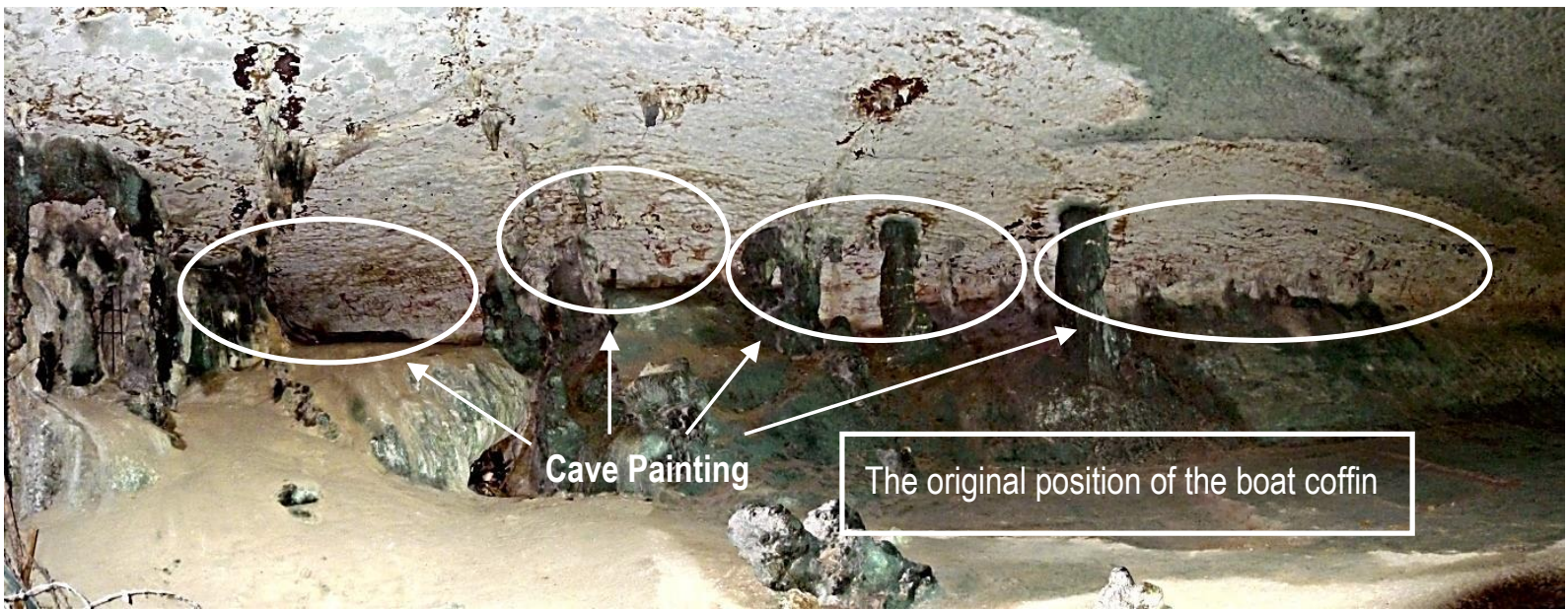

Fig.5: Ancient cave paintings located in Kain Hitam Cave (Painted Cave).

Interpretation is a way of thinking about the quality of communications and services provided to visitors. This method was used to convey a message or story about a site effectively. Without a good variety of interpretation, the locations of this omission would be unattractive and dull. As a result, visitors can not feel anything special and cannot rely on these prehistoric relics. These ancient heritage sites require interpretation methods to attract tourists. Interpretation is a value-added and brings substantial benefits to a location of relics. Without it, these sites are like an empty shell and lose valuable opportunities. 


\subsection{Conclusion}

Every nation and society around the world has a unique ancient cave painting culture that can be the gauge of today's generation. It reflects the creative expression of an ancient civilization. It shows that human activity in the past was universally occurring in visual form. The creation of cave paintings is also in line with the history of the development of human culture and our knowledge of the prehistoric society culture. Recording images activities in this cave painting are essential as an effort to preserve the heritage left by the ancient societies. As a valuable national treasure, this heritage source should also be protected through the preservation and conservation activities of various aspects. This research is an attempt to record the images of cave paintings found in Kain Hitam (Painted Cave) Niah, Sarawak. Malaysia has so many limestone landscapes, long mountain ranges, and valleys covered by many caves and rocks. The people inhabiting the interior and the cave refer to prehistoric communities and other indigenous peoples who have lived or sheltered in the cave (Sanim Ahmad, 2006). Archaeological research and excavations in Malaysia seek to find a wide variety of artifacts in the cave. The discovery of various artifacts such as stone tools, pottery, human skeletons, and even cave paintings indicates that the past has used the cave for a long time. Archaeological sites in the largest caves are been found throughout Malaysia. In addition to artifacts, the discovery of cave paintings suggests that communities have since been in high ideals or creativity in translating their daily activities in the form of cave paintings or pictographs.

\section{Acknowledgments}

The authors gratefully acknowledge funding from the Center for Research and Innovation (PPI), Universiti Malaysia Sabah in providing UMSGreat research grant scheme (Project Number: GUG0216-1 / 2018) and sponsored by the Sarawak Scholarship Foundation Tunku Abdul Rahman (YBSTAR) from the Sarawak State Foundation for a doctorate in Philosophy. The authors also thank the State Planning Unit (SPU), Chief Minister Department (Reference: (40) JKM / SPU / 608-8 / 2/1 VOL.2) for permitting to research in Sarawak. In appreciation of Mr. Mohd. Sherman bin Sauffi, as Director of the Archeological Section, Department of Museums Sarawak, had supervised and conducted this research on the site and also thanked all the staff members of the Sarawak Museum for their excellent cooperation in providing information from the archives collections used in this research.

\section{References}

Sarawak's Heritage. Ministry of Environment and Tourism, Sarawak, Malaysia.

Achmad Sopandi Hasan. (2003). Lukisan Gua di Malaysia. Kuala Lumpur: Balai Seni Lukis Negara.

Adams, M.J. (1977). A "Forgotten" Bronze Ship and Recently Discovered Bronze Weaver from Eastern Indonesia: A Problem Paper. Asian Perspectives (20): 87-109.

Ballard, C., R. Bradley, L. Nordenborg M., and M. Wilson. (2004). The ship as a symbol in the prehistory of Scandinavia and Southeast Asia. World Archaeology (35): $385-403$

Bellwood, P. (1997). Prehistory of the Indo-Malaysian Archipelago, Revised edition. Honolulu: University of Hawaii Press.

Chêng, T. (1969). Archaeology in Sarawak. Cambridge: W. Heffer and Sons and the University of Toronto Press.

Erwin Panofsky. (1939). Studies in Iconology: Humanistic Themes in the Art of the Renaissance. Oxford University Press.

Harrisson, B. (1964). Archeology Borneo: Recent Archeological Discoveries in Malaysia 1962-1963. Borneo. JMBRAS Volume (XXXVII), Part 2. November 1964, page 192-206.

Harrisson, T. (1960). Stone Age Ships of Death: World's Oldest Boat Coffins found in Sarawak caverns reveal ancient culture. Life, January 11, 1960, page 49-51.

Harrisson, T. (1958). The Great Cave Sarawak: A Ship-Of-The-Dead Cult and Related Rock Paintings, The Archaeological Newsletter. (6):199-204.

Lape, P., S. O'Connor, and N. Burningham (2007). Rock Art: A Potential Source of Information about Past Maritime Technology in the South-East-Asia-Pacific Region International Journal of National Archaeology (36):238-253.

Sanim Ahmad. (2006). Lukisan Primitif Gua Batu Kapur Malaysia II. Jurnal Arkeologi Malaysia. Edisi 19. Kuala Lumpur: Universiti Kebangsaan Malaysia.

Szabó, K. In preparation. The Molluscan Remains from the Niah Caves. In G. Barker, D. Gilbertson and T. Reynolds (eds), The Archeology of the Niah Caves, Sarawak: Excavations 1954-2004. Vol.2. Cambridge: McDonald Institute for Archaeological Research.

Szabó, K., Piper P. J., Barker, G. (2008). Sailing between worlds: The symbolism of death in northwest Borneo. Terra Australis (29); page 149-170.

Wairah Marzuki (2001). Seni, Alam dan Kenegaraan. Kuala Lumpur: Balai Seni Lukis Negara.

Zuraina M. (1982). The West Mouth, Niah in Prehistory of Southeast Asia. Sarawak Museum Journal 31(3): 1-200. 